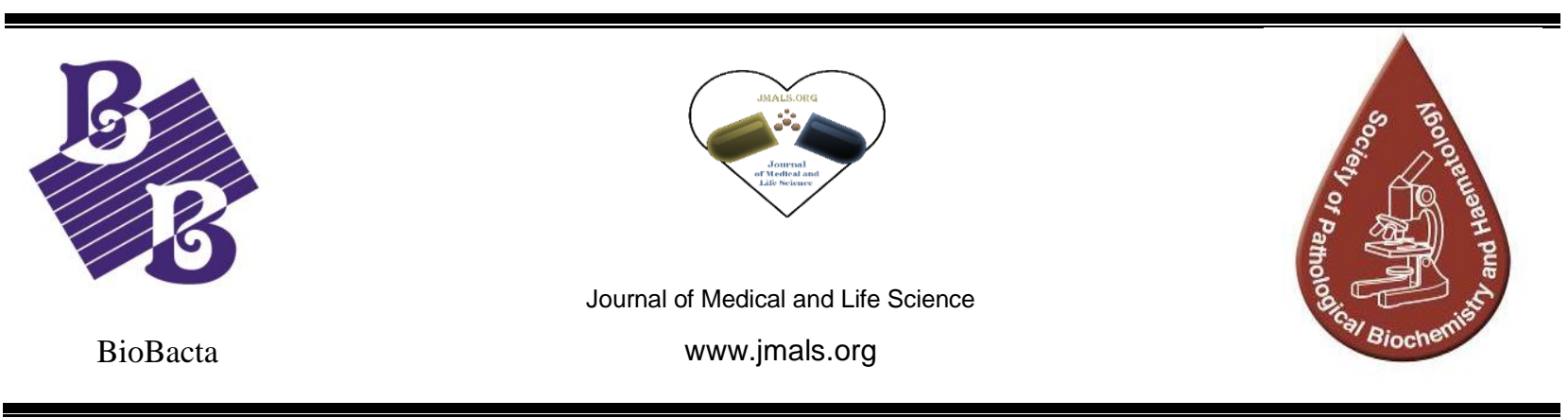

\title{
Biochemical Risk Factors for Kidney Stones in Diabetic Patients
}

\author{
Ahmed Hamzawy ${ }^{1}$, Aida Hussein ${ }^{2}$, Ammar Ghobish ${ }^{3}$, Zohour Nabil ${ }^{4} *$ \\ 1 Suez General Hospital, Suez, Egypt. \\ 2 Zoology Department, Faculty of Science; Suez University, Suez, Egypt. \\ 3 Urology Department, Faculty of Medicine, Suez Canal University, Ismailia, Egypt. \\ 4 Zoology Department, Faculty of Science, Suez Canal University, Ismailia, Egypt.
}

\begin{abstract}
:
Objective: The aim of this study is to investigate the biochemical risk factors of kidney stones in diabetes. This includes the estimation of serum and urinary creatinine $(\mathrm{Cr})$, albumin $(\mathrm{Alb})$, sodium $\left(\mathrm{Na}^{+}\right)$, potassium $\left(\mathrm{K}^{+}\right)$, magnesium $\left(\mathrm{Mg}^{++}\right)$, phosphorous $\left(\mathrm{Po}_{4}{ }^{++}\right)$, calcium $\left(\mathrm{Ca}^{++}\right)$, uric Acid (U.A), alkaline phosphatase (ALP), serum parathyroid hormone $(\mathrm{PTH})$, reduced glutathione levels $(\mathrm{GSH})$, urinary Oxalate, as well as citrate and nitric oxide (NO) levels were measured. Subjects and Methods: The clinical study was performed on 100 patients that attended Suez Health Insurance Organization and Ain Elhyah Hospital. Patients were divided into four groups; 25 diabetic patients (D) (mean age 52); 25 renal stone patients (R, S) (mean age 49); 25 diabetic renal stone patients (D R S)(mean age 51) and 25 control subjects (C)((mean age 47) age-matched, randomly selected. Blood and urine $24 \mathrm{hr}$ samples were collected. Results: Serum $(\mathrm{Cr})$ and (Alb) levels showed a non-significant changes in all patients. However, the data showed a significant decrease in $\left(\mathrm{Mg}^{++}\right)$level of all patients groups, with a significant level in (D R S) than (D) and (R, S) patients. Moreover, a significant increase in (U.A) levels of all patients groups but higher in (DRS) than (D) and (R, S) patients groups. the data revealed a significant decrease in urinary magnesium level in(DRS) patients group compared to (C), (R, S) and (D) patients groups. Moreover, a significant increase in urinary (U.A) level of all patients was noticed, it was significantly higher level in (DRS) than $(\mathrm{R}, \mathrm{S})$ patients groups. Oxalate level in all patients was increased, significantly. Meanwhile, the oxalate level was increased in (DRS) compared to (R, S) and (D) patients groups. The citrate level was decreased significantly in the urine of all patients groups with a significantly lower level of (DRS) than (R, S) and (D) patients groups. On other hands, a significant decrease in blood GSH level of all patients groups was observed where; its level in (DRS) was significantly lower than the (R, S) patients groups. However, data revealed a significant increase in serum (PTH) level of the (R, S) and (D R S) patients groups compared to (C) one. PTH level in (R, S) patients group was significantly higher than (D) and (DRS) patients groups. The data revealed a significant increase in serum ALP level of (D) and (D R S) groups compared to (C) group with a higher significant level in (DRS) than $(\mathrm{R}, \mathrm{S})$ patients groups. Moreover, the urinary $24 \mathrm{~h}(\mathrm{NO})$ level was increased significantly in all patients groups compared to $(\mathrm{C})$ group.
\end{abstract}

Keywords:diabetes (D), renal Stone (R, S), renal function, (U.A), $\left(\mathrm{Mg}^{++}\right), \mathrm{PTH}, \mathrm{GSH}$. 


\section{Introduction}

Diabetes Mellitus has reached epidemic proportions among the challenging unresolved health problems. Around 230 million people worldwide have been affected by diabetes and around 366 million people are expected to get affected by 2030 (Wild et al., 2004 B). Egypt is currently in the top 10 countries with the highest number of people with diabetes and maybe reach 7.6 million Egyptians will have the disease by 2025(Williams and Pickup, 2004). In addition to the primary effects of diabetes, (DM) can lead to complications over time. These complications include an increased incidence of renal stones. (Williams and Pickup, 2004; Reusch and Drazin, 2007).Oxidative stress is currently suggested as a mechanism underlying diabetes and diabetic complications (Aronson, 2008; Moussa 2008). During diabetes, persistent hyperglycemia causes increased production of free radicals, especially reactive oxygen species (ROS), for all tissues leading to glucose-autooxidation, protein glycosylation. The level of these antioxidant enzymes critically influences the susceptibility of various tissues to oxidative stress and is associated with the development of complications in diabetes (Lipinski, 2001). It was reported that oxalate crystals induce free radicals formation in the body which may cause damage to body cells, particularly the cells of the renal tubules. This is one of the reasons that make this type of patients with kidney stones and recurrence of stones. A kidney stone is a common, worldwide disease. So far, precise mechanisms for stone formation and pathophysiologic of the disease have not been fully discovered. Some studies indicated that diabetic patients have increased incidence of kidney stone. Investigations indicated that the change that occurs in the physiological and biochemical properties of urine related to diabetes has the potential to be a factor in the formation of kidney stones. Recently, it was reported that increase the acidity of urine leads to the formation of uric acid stones (Medindia, 2012).

2. Material and Methods-: The clinical study was performed on 100 patients that attended Suez Health Insurance Organization and Ain Elhyah Hospital.
Patients were divided into four groups; 25 insulindependent (IDDM) diabetic patients (mean age 52); 25 renal stone patients (mean age 48.5); 25 diabetic renal stone patients (mean age 51) and 25 control subjects (mean age 47) age-matched, randomly selected. Blood and urine $24 \mathrm{~h}$ samples were collected after agreement of patients and informing them about everything under 6-8 hours fasting, by vein puncture.

Blood and urine 24 samplings: Apart from the blood sample was allowed to clot and then centrifuged at $4000 \mathrm{rpm}$ for 10 minutes. Serum was separated and then frozen at $-20^{\circ} \mathrm{C}$ till biochemical analyses were performed. The rest of the blood sample was collected in tubes containing EDTA to prevent clotting, where it was used for (GSH) measurement. On other hands, urine 24 samples were collected and biochemical analyses were performed on.

Biochemical measurements: The measurements were carried out on Serum Parameters, 24 hr Urinary Parameters as the following: Serum renal function tests $\left(\mathrm{Cr}\right.$, and U.A), ions as $\left(\mathrm{Na}^{+}, \mathrm{K}^{+} \mathrm{Po} 4^{++}, \mathrm{Mg}^{++}\right)$ liver function as (Alb, Ca and ALP), (PTH) and whole blood(GSH). In the meantime, $24 \mathrm{hr}$ urine parameters as $\left(\mathrm{Na}^{+}, \mathrm{K}^{+} \mathrm{Ca}, \mathrm{Po}^{++}, \mathrm{Mg}^{++}\right.$, U.A oxalate, and citrate) Also, the urinary NO level was measured. These all measurements were analyzed by the automated laboratory system; Beckman coulter (Au 480, USA) where biochemical reagents of Beckman coulter were used. Determination of (GSH)was estimated in whole blood following the method of (Beulteret al., 1963) whereas the concentration of total nitric oxide in urine $24 \mathrm{hr}$ was estimated following(Montgomery and Dymock, 1961)method using Bio diagnostics kit, USA.

Whole blood reduced glutathione (GSH): The whole blood reduced glutathione (GSH) content was determined by the method of Beulter $\boldsymbol{e t}$ al. To $0.2 \mathrm{ml}$ of whole blood, $1.8 \mathrm{ml}$ of distilled water and $3.0 \mathrm{ml}$ of precipitating solution (5\% TCA and 1mM EDTA) were added and mixed. This mixture was incubated at room temperature for 10 minutes. The mixture was 
centrifuged at $3500 \mathrm{~g}$ for 10 minutes. To $1.5 \mathrm{ml}$ of the supernatant, $2.5 \mathrm{ml}$ of $\mathrm{Na}_{2} \mathrm{HPO}_{4}(0.3 \mathrm{M})$ and $3.0 \mathrm{ml}$ of dithionitro benzoic acid ( $0.4 \%$ DTNB and $1 \%$ sodium citrate) were added. This mixture was incubated at room temperature for 30 minutes. After 30 minutes of incubation, the absorbance was measured at $412 \mathrm{~nm}$. A standard graph was drawn using reduced glutathione as standard and the reduced glutathione concentration in the samples was calculated.

Statistical Analysis: Data were analyzed using SPSS statistical software (SPSS/10 for Windows). ANOVA test and subsequent post-hoc multiple comparison analysis were used to estimate statistical differences between groups. All parameters were given as means \pm standard error (SEM). The criterion for significance was $P<0.05$.

3. I) Results (Serum Analysis): Data of this work revealed a non-significant change in serum creatinine and albumin level in all patient groups which (P-value $>0.05$ ) as shown (Table 1).However, the data showed a significant decrease in $\left(\mathrm{Mg}^{++}\right)$level in all patients groups compared to control one, with a significantly lower level in (D R S) than (D) and (R, S) patients groups. Data revealed a non-significant change in phosphorus level in all patients groups compared to control one, with an increase in (D R S) patients group over (R, S) one, as shown (Table 2). Moreover, a significant increase in calcium and uric acid level in all patients groups compared to the control one. Calcium level in (D R S) was significantly lower than (R, S) and significantly higher than (D) patients groups. On other hands, the uric acid level was significantly higher in (DRS) than (D) and (R, S) patients groups as shown (Table2).

II)Results (urine $24 \mathrm{~h}$ analysis) represents a significant decrease in $\left(\mathrm{Na}^{+}\right)$and $\left(\mathrm{K}^{+}\right)$levels in all patients groups with a significant decrease in (DRS) than (R, S) patients groups, as shown in (Table 3). Morever, the data revealed a significant decrease in urinary magnesium level in (DRS) patients group compared to $(\mathrm{C}),(\mathrm{R}, \mathrm{S})$ and $(\mathrm{D})$ patients groups as shown (Table 3). Moreover, a significant increase in calcium and uric acid level in the urine in all patients groups compared to the control one. Also, calcium and uric acid levels in (DRS) were significantly higher than $(\mathrm{R}, \mathrm{S})$ patients groups as shown in (Table 3). Urinary $\left(\mathrm{Po}_{4}{ }^{++}\right)$level, showed a significant increase in its level of (DRS) patients groups compared to (C) one, also in (Table 3). Oxalate level in all patients groups was increased significantly compared to control one. Meanwhile, the oxalate level showed a significant increase in (DRS) compared to (R, S) and (D) patients groups. On other hand, citrate level was decreased significantly in urine in all patients groups with a significant decrease in citrate level of (DRS) than (R, S) and (D) patients groups, as shown in (Table3). A significant decrease in GSH level in all patients groups compared to control one was noticed in (Table 4), the GSH level in (DRS) was significantly lower than the $(\mathrm{R}, \mathrm{S})$ patients groups. Data revealed a significant increase in PTH level in (D R S) patients group compared to (C) and (D) patients groups, as shown (Table 4). The data revealed a significant increase in the ALP level of (D R S) patients group compared to (C) and (R, S) patients groups, as shown (Table4). Moreover, Nitric oxide level was increased significantly in all patients compared to (C) one, as shown (Table 4). 
Table 1: Age, Sex, Serum Creatinine and Albumin level in Control, Stone, Diabetic and Diabetic stone groups

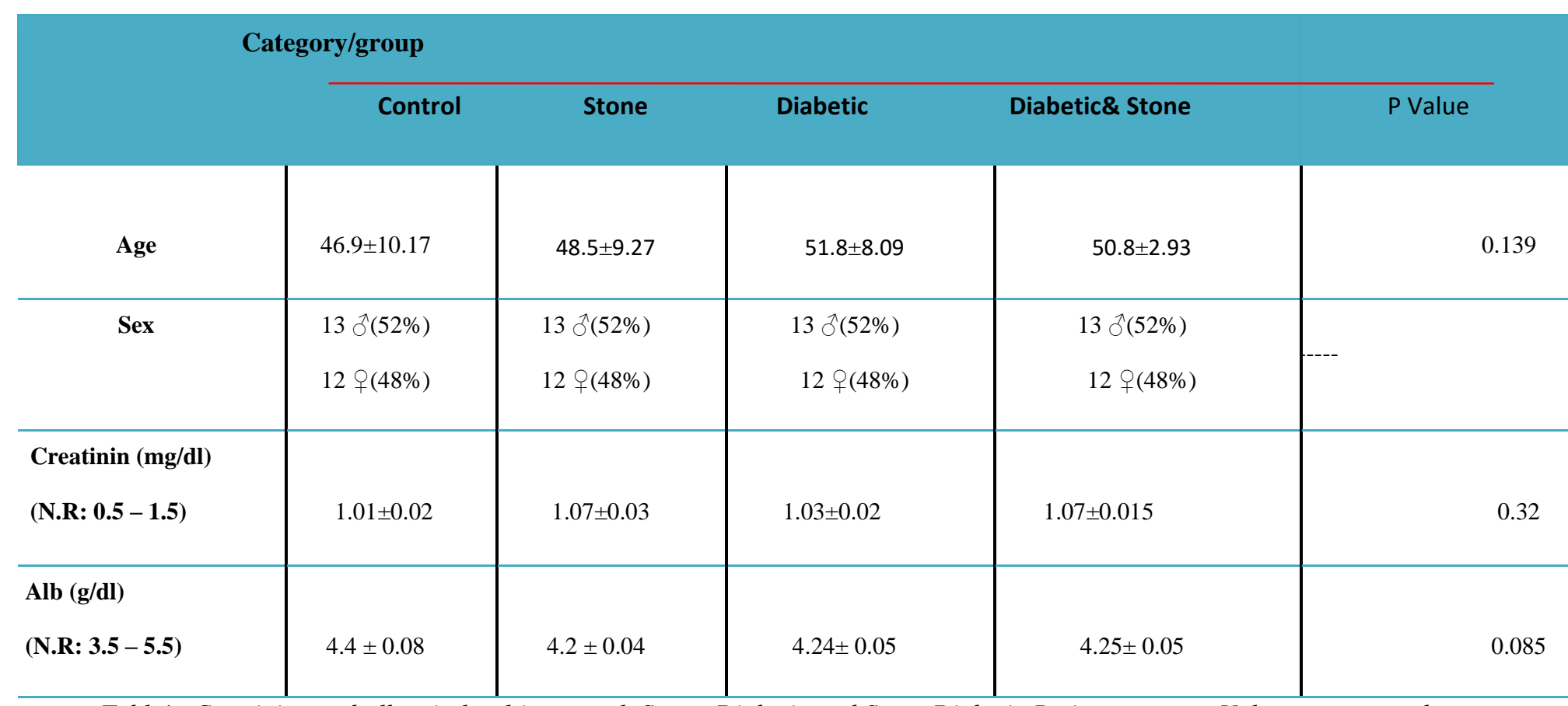

Table1: Creatinine and albumin level in control, Stone, Diabetic and Stone Diabetic Patients groups. Values represented as mean $\pm S E$. Indicates a non significant difference between patients groups $(P>0.05)$.

Table 2: Serum biochemical parameters $\left(\mathrm{Na}^{+}, \mathrm{K}^{+}, \mathrm{Mg}^{++}, \mathrm{Po}_{4}^{++}, \mathrm{Ca}^{++}, \mathrm{U} . A\right.$ and ALP) levels in Control, Stone, Diabetic and Diabetic stone groups.

\begin{tabular}{|c|c|c|c|c|c|}
\hline \multicolumn{6}{|c|}{ Category/group } \\
\hline \multicolumn{2}{|c|}{ Control } & Stone & \multicolumn{2}{|c|}{ Diabetic\& Stone } & ' Value \\
\hline $\begin{array}{l}\begin{array}{l}\text { Magnesium } \\
(\mathbf{m g} / \mathbf{d l})\end{array} \\
\quad \text { (N.R: } 1.8-\mathbf{2 . 4})\end{array}$ & $2.1 \pm 0.03$ & $1.97 \pm 0.029^{\mathrm{a}}$ & $1.9 \pm 0.022^{\mathrm{a}}$ & $1.8 \pm 0.04^{\mathrm{a}, \mathrm{b}, \mathrm{c}}$ & $<0.0001^{* * * *}$ \\
\hline \begin{tabular}{|l}
$\begin{array}{l}\text { Phosphorous } \\
\text { (mg/dl) }\end{array}$ \\
(N.R: 2.5 - 4.5)
\end{tabular} & $3.88 \pm 0.076$ & $3.4 \pm 0.11^{\mathrm{a}}$ & $3.85 \pm 0.079^{b}$ & $3.99 \pm 0.166^{\mathrm{b}}$ & $0.002^{* *}$ \\
\hline $\begin{array}{c}\text { Calcium (mg/dl) } \\
\text { (N.R: } 8-10)\end{array}$ & $8.12 \pm 0.06$ & $10.2 \pm 0.26^{\mathrm{a}}$ & $8.9 \pm 0.13^{\mathrm{a}, \mathrm{b}}$ & $9.35 \pm 0.19^{\text {a,b,c }}$ & $<0.0001^{* * *}$ \\
\hline $\begin{array}{l}\text { Uric acid(mg/dl) } \\
\quad(N . R: 3-6)\end{array}$ & $3.33 \pm 0.1$ & $6.02 \pm 0.3^{\mathrm{a}}$ & $6.26 \pm 0.27^{\mathrm{a}}$ & $7.66 \pm 0.37 \mathrm{a}$ a,bc & $0.0001^{* * *}$ \\
\hline
\end{tabular}

Table2: Serum biochemical parameters $\left(\mathrm{Mg}^{++}, \mathrm{Po}_{4}{ }^{++}, \mathrm{Ca}{ }^{++}\right.$and U.A) levels in Control (C), Stone (R, S), Diabetic (D) and Diabetic stone (DRS)patients groups. a Indicates a significant difference between $(R, S),(D)$ and (DRS) versus control using Student's unpaired t-test, $\boldsymbol{b}$ indicates a significant difference between (DRS) and $(D)$ versus $(R, S)$ using ANOVA test, whereas $C$ indicates a significant difference between (D) and (DRS) using ANOVA test (P <0.05). 
Table 3: Urine $24 \mathrm{hr}$ biochemical parameters $\left(\mathrm{Na}^{+}, \mathrm{K}^{+}, \mathrm{Mg}^{++}\right.$and $\mathrm{Po}_{4}^{++}, \mathrm{Ca++}, \mathrm{U} . \mathrm{A}$, Oxalate and Citrate) levels in Control, Stone, Diabetic and Diabetic stone groups.

\section{Category/group}

\section{Control \\ Stone \\ Diabetic \\ Diabetic\& Stone}

P Value

\begin{tabular}{|c|c|c|c|c|c|}
\hline $\begin{array}{l}\text { Sodium }(\mathrm{mmol} / \mathbf{2 4 h}) \\
\text { (N.R: } 40-\mathbf{2 2 0})\end{array}$ & $102.4 \pm 1.13$ & $84.5 \pm 3.66^{\mathrm{a}}$ & $84.13 \pm 6.8^{\mathrm{a}}$ & $71.6 \pm 2.68^{\mathrm{a}, \mathrm{b}}$ & $0.00001^{* * * *}$ \\
\hline $\begin{array}{l}\text { Potassium }(\mathrm{mmol} / 24 \mathrm{~h} \\
\text { (N.R: } 25-125)\end{array}$ & $99.02 \pm 2.25$ & $59.4 \pm 4.17^{\mathrm{a}}$ & $37.14 \pm 5.19^{a}$ & $30.86 \pm 2.76^{\mathrm{a}, \mathrm{b}}$ & $<0.0001^{* * *}$ \\
\hline $\begin{array}{l}\text { Magnesium }(\mathrm{mg} / 24 \mathrm{~h}) \\
\text { (N.R: } 30 \text { - 180) }\end{array}$ & $36.7 \pm 2.42$ & $21.4 \pm 2.3^{\mathrm{a}}$ & $42.9 \pm 1.61^{\mathrm{a}, \mathrm{b}}$ & $19.9 \pm 2.18^{\mathrm{a}, \mathrm{b}, \mathrm{c}}$ & $<0.0001^{* * *}$ \\
\hline $\begin{array}{c}\text { Phosphorous (g/24h) } \\
\text { (N.R: } 0.4-1.3)\end{array}$ & $0.44 \pm 0.01$ & $0.57 \pm 0.023^{a}$ & $0.493 \pm 0.029$ & $0.51 \pm 0.02^{\mathrm{a}}$ & $0.001^{* *}$ \\
\hline $\begin{array}{l}\text { Calcium }(\mathrm{mg} / \mathbf{2 4 h}) \\
\text { (N.R: } 100-\mathbf{3 0 0 )}\end{array}$ & $127 \pm 6.22$ & $147.2 \pm 3.9^{\mathrm{a}}$ & $150.3 \pm 9.3^{\mathrm{a}}$ & $177.9 \pm 0.19^{\mathrm{a}, \mathrm{b}}$ & $0.002^{* *}$ \\
\hline $\begin{array}{l}\text { Uric acid(mg/24h) } \\
\text { (N.R: } 250-750)\end{array}$ & $300.9 \pm 10.9$ & $437.8 \pm 26^{\mathrm{a}}$ & $552.9 \pm 22.2^{\mathrm{a}, \mathrm{b}}$ & $598.8 \pm 23.3^{\mathrm{a}, \mathrm{b}}$ & $<0.0001^{* * *}$ \\
\hline $\begin{array}{l}\text { Oxalate }(\mathrm{mmol} / 24 \mathrm{~h}) \\
\text { (N.R: } 0.08-0.49)\end{array}$ & $0.1 \pm 0.006$ & $0.53 \pm 0.02^{\mathrm{a}}$ & $0.17 \pm 0.008^{\mathrm{a}, \mathrm{b}}$ & $0.25 \pm 0.017^{\mathrm{a}, \mathrm{b}, \mathrm{c}}$ & $<0.0001^{* *}$ \\
\hline $\begin{array}{l}\text { Citrate }(\mathrm{mg} / 24 \mathrm{~h}) \\
\qquad(300-\mathbf{8 5 0})\end{array}$ & $632.8 \pm 5.7$ & $262.6 \pm 3.35^{\mathrm{a}}$ & $403.6 \pm 5.78^{\mathrm{a}, \mathrm{b}}$ & $130.4 \pm 1.28^{\mathrm{a}, \mathrm{b}, \mathrm{c}}$ & $<0.0001^{* *}$ \\
\hline
\end{tabular}

Table3: Urine $24 \mathrm{hr}$ biochemical parameters $\left(\mathrm{Na}^{+}, \mathrm{K}^{+}, \mathrm{Mg}^{++}, \mathrm{Po}_{4}^{++}, \mathrm{Ca}++\right.$, U.A, oxalate and citrate) levels in Control (C), Stone (R, S), Diabetic (D) and Diabetic stone (DRS) patients groups. a Indicatesa significant difference between (R, S), (D) and (DRS) versus (C) using Student's unpaired t-test, bindicatesa significant difference between (D) and (DRS)versus(R, S) using ANOVA test, whereasCindicatesa significant difference between (D) and (DRS) using ANOVA test $(\mathrm{P}<0.05)$. 
Table4: Blood GSH, Serum PTH andUrine 24 h NO levels inControl, Stone, Diabetic and Diabetic stone groups

\section{Category/group}

Control

Stone

Diabetic

Diabetic\& Stone

P Value

\begin{tabular}{|c|c|c|c|c|c|}
\hline $\begin{array}{c}\text { Blood GSH (micro mol/L) } \\
\text { M(>= 569) , F } \quad(>=450) \\
\text { No: within normal range=18 } \\
\text { High }=82\end{array}$ & $589.7 \pm 44.5$ & $284.5 \pm 13.47^{a}$ & $272 \pm 19.49^{\mathrm{a}}$ & $200 \pm 17.98^{a, b, c}$ & $<0.00001^{* * * *}$ \\
\hline $\begin{array}{l}\begin{array}{l}\text { Serum PTH }(\mathrm{pg} / \mathrm{mL}) \\
\quad(10-69)\end{array} \\
\text { No: within normal range=92 } \\
\text { High }=8\end{array}$ & $16.04 \pm 0.9$ & $54.66 \pm 4.15^{\mathrm{a}}$ & $17 \pm 1.59^{\mathrm{b}}$ & $34.44 \pm 2.8^{\mathrm{a}, \mathrm{b}, \mathrm{c}}$ & $<0.00001^{* * * *}$ \\
\hline $\begin{array}{c}\operatorname{ALP}(\mathbf{u} / \mathbf{l}) \\
(\text { N.R: } 30-120)\end{array}$ & $64.7 \pm 3.2$ & $61.9 \pm 2.49$ & $99.77 \pm 3.6^{\mathrm{a}, \mathrm{b}}$ & $109.9 \pm 3.7^{\mathrm{a}, \mathrm{b}}$ & $<0.0001^{* * *}$ \\
\hline $\begin{array}{l}\text { Urinary NO }(\mathrm{mmol} / 24 \mathrm{~h}) \\
(10-72) \\
\text { No: within normal range=81 } \\
\text { High }=19\end{array}$ & $18.4 \pm 3.42$ & $61.39 \pm 13.2^{\mathrm{a}}$ & $49.47 \pm 12.2^{\mathrm{a}}$ & $54.87 \pm 10.8^{a}$ & $0.026^{*}$ \\
\hline
\end{tabular}

Table4: Blood (GSH), serum (PTH), serum (ALP) and urine 24h (NO) levelsin Control (C), Renal Stone (R, S), Diabetic (D) and Diabetic Renal Stone (DRS) patients groups. a Indicatesa significant difference between (R, S), (D) and (DRS) versus (C) using Student's unpaired t-test, bindicatesa significant difference between (D) and (DRS)versus $(\mathrm{R}, \mathrm{S})$ using ANOVA test, whereasCindicatesa significant difference between (D) and (DRS) using ANOVA test (P $<0.05)$.

\section{Discussion}

This study showed a significant decrease in groups compared to $(C),(R, S)$ and (D) patient $\left(\mathrm{Mg}^{++}\right)$level in all patients groups compared to groups. These results in renal stone patients may control one, with a significantly lower level in (D be due to renal loss which causes hypomagnesemia, R S) than (D) and (R, S) patients groups. this hypothesis was agree also with Preminger Moreover, the data revealed a significant decrease (2003) who stated that if oxalate increase; in urinary magnesium level in (DRS) patient magnesium as one of the stone inhibitors will 
complex with the excess oxalate, causing more consumption of magnesium, so its level will decrease, as stated also by Soundararajan et al. (2006). In the present study serum and urinary uric acid levels showed a significant increase in all patients compared to the control group. These results indicate that in nephrolithiasis, where, the glomerular filtration rate (GFR) decreases due to the obstruction to the outflow of urine by stones present in urinary tract, because of that waste product, particularly the nitrogenous substances, as uric acid which accumulate in patient's blood (Hossein et al., 2010, Prasobhand Revikumar, 2012 ). Moreover, in the present study; the urinary oxalate level was investigated in all patient groups, where, oxalate level showed a significant increase in (DRS) compared to $(\mathrm{R}, \mathrm{S})$ and (D) patients groups. The level of oxalate significantly increased, where it may be due to the decrease of dietary calcium intake, leading to imbalance between calcium and oxalate in gastrointestinal tract, so no sufficient amount of calcium binds with oxalate in intestinal lumen, resulting an increase in oxalate excretion in urine and increased risk of stone formation as previously reported by Curhanet al., (1997) and Sandhya et al. (2010); meanwhile, the increase in dietary oxalate may cause an increase the availability of substrate (ascorbic acid, ethylene glycol, methoxyflurane), reduced degradation of oxalate by intestinal bacteria leads to an imbalance between intraluminal calcium and oxalate, this hypothesis agrees with (Connellet al., 2002; Arq, 2006). Our results showed a significant decrease in urinary citrate levels in all patients, with a significant decrease in the level of (DRS) than (R, S) and (D) patient groups. The decrease in citrate level may be due to the high level of (PTH) may cause an increased calcium level leading to more citrate which chelates with urinary calcium and preventing precipitation of calcium salts, the more consumption of citrate chelate with calcium, consequently, citrate level was reduced, this hypothesis agree with Sharoun (2008), moreover, may be directly caused by low dietary citrate. In the present study, the results revealed a significant decrease in blood (GSH) levels in all patient groups compared to control. GSH level in (DRS) was significantly lower than the $(\mathrm{R}, \mathrm{S})$ patients groups. The significant decrease in (GSH) level may be due to the direct reaction between (GSH) 
and the free radicals generated due to diabetes and stone formation, which leads to the oxidation of cellular lipids, proteins, nucleic acids, glycolipids, and glycoproteins. This is consistent with (GSH) function to cope with oxidative stress locally and systemically through scavenging oxidants by binding them covalently causing more consumption and decrease in GSH levels, as previously reported by (Yue et al.,2016; Ming et L.,2014; Ismail and Murat, 2013; Kriang et al., 2005; Yoshida et al.,1995). In this study, serum (PTH) was investigated in all patients groups, where the results showed a significant increase in PTH levels of all patient groups compared to control, with a significantly higher level in (DRS) than (C) and $(\mathrm{R}, \mathrm{S})$ patients groups. The significant increase in (PTH) level may be due to function of a kidney that doesn't respond normally to more (PTH), due to the nephrolithiasis and the oxidative stress occurred on $(\mathrm{R}$, S) and (DRS) patient groups, this hypothesis agrees with Harleen et al. (2001). In this study, the results showed a significant increase in serum alkaline phosphatase (ALP) level in (D) and (DRS) patients. The significant increase of the ALP level is a strong indicator of hepatic impairment, as previously discussed by (Warrag et al.,2014). Urinary nitric oxide (NO) level was investigated in this study, in all patient groups where NO levels increased significantly in all groups when compared to control group; This increase might be due to the increase of oxalate excretion and deposition of calcium oxalate crystals in renal tubules, which associate with renal epithelial injury, and produces cellular damage, that causes an increase of reactive oxygen (nitrogen) production, which intermediates with RO $(\mathrm{N})$. The generation of reactive oxygen and reactive nitrogen species may result from the formation of the cystolic metabolite peroxynitrite that causes nitrosative stress leading to inflammatory events as previously reported by Sandhya et al. (2010).

5. Conclusion: This study demonstrated that diabetes patients suffering from renal stone disease are affected in 24 parameters in serum and urine, leading to increase in serum calcium $\left(\mathrm{Ca}^{++}\right)$and uric acid levels, and decrease in serum magnesium level; moreover, increasing urinary $24 \mathrm{hr}$ uric acid, calcium, and oxalate levels, and decrease in magnesium and citrate levels. In addition, parathyroid hormone and urinary nitric oxide levels increased, accompanied by a decrease in blood reduced glutathione level. 


\section{References :}

Aronson D (2008): Hyperglycemia and the pathobiology of diabetic complications. Adv. Cardiol., 45: 1-16.

Arq B. (2006): Renal Stone Disease: Causes, Evaluation and Medical Treatment. Endocrinal Metab. 50 (4): 823-831.

Beulter E, Duron O and Kelly BM (1963): Improved method for the determination of blood glutathione. J Lab Clin Med.61:882-888.

Connell N, Campbell S, Gillanders I, Rolton H and Danesh B. (2002): Risk Factors for Developing Renal Stones in Inflammatory Bowel Disease. BJU Int; 89(9):835-41.

Curhan G, Willet W and Speizer F. (1997): Comparison of Dietary Calcium with Supplemental Calcium and other Nutrients as Factors Affecting the Risk for Kidney Stones in Women. Ann Inter Med 126:497.

Harleen Jaggi, MT(ASCP), CLS (NCA)1, and Ellen Hope Kearns, MS, SH(ASCP)H (2001): Primary Hyperthyroidism. chemistry | generalist | immunology. 2 (32).

Hossein H, Ali R and Zahra K. (2010): Antiurolithiatic activity of Pinus Eldarica Medw. Fruits aqueous extracts in rats. J Uro1;7:232-7.

Ismail H and Murat S (2013): The relationship between the level of glutathione, impairment of glucose metabolism and complications of diabetes mellitus. J of Med Sci. 29(4): 938-942.

Kriang T, Pote S, Prasit F, Chatchai Y, Piyaratana (2005): Renal tubular cell damage and oxidative stress in renal stone patients and the effect of potassium citrate treatment. Urol. J., 33: 65-69.
Lipinski B (2001): Pathophysiology of Oxidative stress in Diabetes mellitus.: $\mathrm{J}$ of Diab and its Complic. 15: 203-210.

Medindia M (2012): Risk of Kidney Stones Increases With Obesity, Diabetes, andGout."Availableat:http://www.medindia.net/ news/healthwatch/risk-of-kidney-stonesincreases-with-obesity-diabetes-and-gout102619-1.htm.

MingC, Yih S, Ho-Shiang H: (2014): Erythrocyte Oxidative Stress in Patients with Calcium Oxalate Stones Correlates with Stone Size and Renal Tubular Damage. Urol. J., 83(2):510.e9510.e17.

Montgomery, H.A.C. and . Dymock (1961): Colorimetric determination of nitric oxide. Analyst. 86: 414-417.

Moussa A, (2008): Oxidative stress in diabetes mellitus. Biophysics. 18 (3): 225-236.

Prasobh G and Revikumar K, (2012): Effect of MUSA Tablet on Ethylene Glycol-Induced Urolithiasis. Int.J in Pharm and Biom Sci. 3 (3): 1251-1255.

Preminger GM. (2003): Editorial J Urol 2003, 170, 402-403.

Reusch J and Draznin B (2007): Atherosclerosis in diabetes and insulin resistance. Diabetes Obese Metabolism. 9:455-463.

Sandhya A, Sandhya D, Sreedevi V, Deepika P and Hema P.(2010): Kidney Stone Disease: Etiology and Evaluation.Int. $\mathbf{J}$ of Applied Biology and Pharm Techn; I (1): 175-182.

Sharoun M. Moe. (2008): Disorders involving Calcium, Phosphorous, and Magnesium. Prim Care.June ; 35(2): 215-vi. 
Soundararajan P, Mahesh R, Ramesh T and Hazeena Begum V (2006): Effect of Aervo Lanata on Calcium Oxalate Urolithiasis. Ind. J of Exp. Bio. ; 44: 981-986.

Warrag N, Tag E and Ahmed E. (2014): Effect of Cymbopogon proximus on EthyleneGlycolInduced nephrolithiasis in rats. 8(17):443-450.

Wild S, Roglic G, Green A, Sicree R and King H (2004b): Global prevalence of diabetes estimates for the year 2000 and projections for 2030. Diabetes care 27:1047-53.

Williams, G., and Pickup, J.C. (2004): Diabetic eydisease. (Blackwell Publishing).
Yoshida K, Hirokawa J, Tagami S, Kawakami Y, Urate Y and Kondo T. (1995): Weakened cellular scavenging activity against oxidative stress in diabetes mellitus: regulation of glutathione synthesis and efflux. Diabeteologia. $38(2): 201-10$.

Yue S, Yaw L, Cara K and Karmin O (2016): Downregulation of Glutathione Biosynthesis Contributes to Oxidative Stress and Liver Dysfunction in Acute Kidney Injury. 22(8):113. 